\title{
A INCLUSÃO DE SURDOCEGOS COM O USO DA TECNOLOGIA ASSISTIVA
}

\author{
ELAINE GOMES VILELA*
}

\begin{abstract}
RESUMO
O presente trabalho foi realizado com apoio da Coordenação de Aperfeiçoamento de Pessoal de Nível Superior - Brasil (CAPES) e tem por objetivo evidenciar as práticas de exclusão social de surdocegos por falta de informação. Essas práticas reforçaram a inacessibilidade aos espaços de conhecimento. Esse artigo investiga as práticas de inclusão no espaço escolar e os recursos de tecnologia assistiva que podem ser utilizados. Nesta perspectiva da escola como lugar propicio de desenvolvimento social, algumas questões estão presentes: Quais práticas pedagógicas podem ser utilizadas? Quais recursos de tecnologia assistiva favorecem a promoção de ensino aprendizagem? Do ponto de vista teórico, algumas referências são citadas, dentre elas: Galvão (2010), Bersch (2006/2008),Eustat (1999) e Sartoreto (2010). Este estudo está fundamentado na abordagem qualitativa na modalidade da pesquisa narrativa desenvolvida por Clandinin e Connelly (2015), na perspectiva autobiográfica a partir das percepções de Creswell (2010). O estudo traz possibilidades de atendimento e de reflexões sobre diretrizes legais que favoreçam o acesso ao ensino, além de citar estratégias e recursos de tecnologia assistiva facili-
\end{abstract}

* Este trabalho é fragmento do terceiro capítulo da pesquisa de mestrado realizada no Programa de Pós-Graduação em Educação da Universidade Metodista de São Paulo (UMESP), intitulada "SURDOCEGOS E OS DESAFIOS NOS PROCESSOS SOCIOEDUCATIVOS: OS MEDIADORES E A TECNOLOGIA ASSISTIVA", defendida em 2018, com a orientação da profa. Dra. Adriana Barroso de Azevedo. 
tadores. a partir das narrativas das experiências dos participantes. Os resultados evidenciam que é necessário um olhar aguçado e sensível para as necessidades dos surdocegos; mas, sobretudo, acreditar nas possibilidades.

Palavras-chave: Inclusão. Surdocegueira. Escola.

\begin{abstract}
This study was financed in part by the Coordenação de Aperfeiçoamento de Pessoal de Nível Superior - Brasil (CAPES), aims to evidence the pratices of social exclusion of deafblinds due to lack of information. This article investigates the inclusion pratices in the school space and assistive technology resources can be used. In this school perspective as a propitious place of social development, some questions are present: What pedagogical practices can be used? What assistive technology resources favor the promotion of teaching learning? From the theoretical point of view, some references are cited, among them: Galvão (2010), Bersch (2006/2008), Eustat (1999) e Sartoreto (2010). This study is based on the qualitative approach in the mode of narrative research developed by Clandinin e Connelly (2015), the autobiographical perspective from the perceptions of Creswell (2010). The study offers possibilities for attendance and reflections on legal guidelines that favor access to teaching, as well as to cite strategies and resources of assistive technology facilitators based on the narratives of participants' experiences. The results show that a sharp and sensitive look is needed for the needs of the deafblind; but, above all, to believe in possibilities.
\end{abstract}

Keywords: Inclusion. Deafblindness. School.

\title{
INTRODUÇÃO
}

Surdocegueira é uma deficiência pouco conhecida e raramente explorada pela literatura brasileira e, ao mesmo tempo, um assunto instigante que causa estranhamento às pessoas que desconhecem tal assunto. De posse das características e singularidades, é possível criar estratégias para o desenvolvimento educacional, cognitivo e social do surdocego. 
Surdocegueira é um termo utilizado para definir a perda da visão e da audição simultaneamente. Por muito tempo ela foi associada a múltiplas deficiências, devido à junção de duas perdas sensoriais, a visual e a auditiva.

Partindo desse pressuposto das perdas sensoriais de dois sentidos, esse artigo faz uma relação do atendimento educacional com as possibilidades de inclusão efetiva mostrando as singularidades dessa deficiência.

A metodologia que orientou a pesquisa de mestrado intitulada: "Surdocegos e os desafios nos processos socioeducativos: os mediadores e a tecnologia assistiva", consistiu na abordagem qualitativa, com utilização de narrativas autobiográficas proposta por Clandinin e Connely (2015), partindo da experiência desta pesquisadora para a experiência dos participantes surdocegos, que emprestaram sua voz e seu olhar à representação das suas vivências. Assim, na perspectiva de Creswell:

A pesquisa qualitativa é uma pesquisa interpretativa, com o investigador tipicamente envolvido em uma experiência sustentada e intensiva com os participantes. Isso introduz uma série de questões estratégicas, éticas e pessoais ao processo de pesquisa qualitativa. (LUCKE et al apud CRESWELL, 2010, p. 211)

O intuito desse artigo é promover conhecimento e compreensão de conceitos teóricos realizados por meio da revisão bibliográfica, desvendando técnicas e práticas, bem como ressignificando a ação de profissionais mediadores no atendimento socioeducacional de surdocegos.

Para elucidar esse atendimento é necessário o uso e a apropriação da Tecnologia Assistiva (TA). Nessa perspectiva a TA se torna essencial para a inclusão efetiva no âmbito educacional, para que se efetive um atendimento de qualidade a todos as pessoas com deficiência. De acordo com Bersch (2006), é necessário buscar formas alternativas de utilização da Tecnologia assistiva: 
Fazer TA na escola é buscar, com criatividade, uma alternativa para que o aluno realize o que deseja ou precisa. É encontrar uma estratégia para que ele possa "fazer" de outro jeito. É valorizar o seu jeito de fazer e aumentar suas capacidades de ação e interação, a partir de suas habilidades. É conhecer e criar novas alternativas para a comunicação, escrita, mobilidade, leitura, brincadeiras e artes, com a utilização de materiais escolares e pedagógicos especiais. É a utilização do computador como alternativa de escrita, fala e acesso ao texto. É prover meios para que o aluno possa desfiar-se a experimentar e conhecer, permitindo assim que construa individual e coletivamente novos conhecimentos. É retirar do aluno o papel de espectador e atribuir-lhe a função de ator. (BERSCH, 2006, p. 89)

Essas colocações da autora são essenciais para o fazer inclusivo dos surdocegos por meio da Tecnologia Assistiva dentro do espaço educacional, pois todas as esferas citadas são passíveis de utilização, como a comunicação, promovida pelo guia-intérprete na mediação; a escrita em Braille; a mobilidade com apoio de estrutura arquitetônica e medição de funcionários para promoção de segurança; a leitura em Braille e letras em relevo; as brincadeiras adaptadas; artes com apoio de materiais diversos.

O surdocego denominado narrador 4 participante da pesquisa menciona a importância de promover o ensino, desde a mais tenra idade, para que as barreiras de acessibilidade sejam as menores possíveis.

Quero deixar um conselho para as crianças, cegas, surdocegas ou baixa visão que usem a bengala e aprendam Braille. Todos que não enxergam, é preciso aprender a ler Braille, memorizar a Libras tátil desde pequenos, para desenvolverem e ser pessoas inteligentes, capazes de serem independentes. (NARRADOR 4)

Este participante acima é engajado no ensino a crianças e adultos, com deficiência ou não, na promoção de acessibilidade. 
Enfatiza sempre a importância da aprendizagem. Outro surdocego participante, Narrador 3 afirma: "A Tecnologia Assistiva, também foi de grande importância na minha vida por que ela fez com que eu vencesse a limitação da surdocegueira. Então, atualmente, ter acesso a esse tipo de tecnologia facilitou muito a minha vida". (NARRADOR 3)

A pesquisadora Bersch (2006) menciona a importância da experimentação na construção da autonomia e da socialização no contato com o outro, propiciando ao aluno a autoria das suas experiências pessoais e coletivas. Essas experiências são construídas à medida que objetivos e sonhos são traçados pelos surdocegos, como ressalta outro participante:

Como eu disse pra vocês eu tenho alguns objetivos. Tenho alguns sonhos e eu me lembro que em 2013, nós estávamos com um projeto de ir à Filipinas, lá na Ásia. E nós conseguimos também realizar esse sonho, que era participar do Congresso Mundial de Surdocegos que, acontece de quatro em quatro anos em um continente. Nós saímos daqui do Brasil, nos preparamos, fomos até às Filipinas e aprendemos muito lá para ensinar aqui no Brasil (NARRADOR 3)

Impressionante a força de vontade e determinação que este participante possui. E presencio todas as suas conquistas como guia-intérprete e amiga. Além de aprender diversas formas de comunicação; ele faz questão de ensinar diferentes guias-intérpretes para que divulguem e ajudem outros surdocegos.

Ainda abordando a relevância da adaptação de recursos de tecnologia assistiva, considero importante destacar que inúmeras vezes adaptei materiais para meus alunos com deficiência sem saber que nome se dava a isso. Hoje, sei que é um recurso de tecnologia assistiva adaptado.

Já engrossei giz de cera com E.V.A. ${ }^{1}$, para que meu aluno com paralisia cerebral pudesse segurar e produzir materiais gráficos; fiz letras ampliadas e contornos em atividades para

1 Acetato-vinilo de Etileno. Uma folha/placa emborrachada, geralmente utilizada em trabalhos artesanais e atividades escolares. 
alunos com baixa visão, entre outras estratégias de ensino para promover acessibilidade.

\section{AVALIAÇÃO DE TECNOLOGIA ASSISTIVA E RECURSOS PEDAGÓGICOS ADAPTADOS}

Antes de produzir qualquer recurso de tecnologia assistiva ou de definir serviço a ser prestado, é necessário fazer uma avaliação das reais necessidades daquele que será beneficiado. Essa preparação é enfatizada por Bersch (2013) que ressalta que devido à facilidade de acesso à internet muitas pessoas acabam por fazer pesquisas de recursos, considerando o grupo ao qual pertence seu aluno, mas sem avaliar as necessidades individuais.

Dessa forma, torna-se imprescindível avaliar o aluno nas suas necessidades individuais, para que se efetive um atendimento inclusivo. A narrativa abaixo é um exemplo de adaptação:

Eu tive que vencer isso também, querido. Vocês estão vendo aquelas plaquinhas ali na minha apresentação [...] quando eu paro nos faróis, eu mostro a plaquinha. Eu mostro que sou surdocego, faço mímica, gestos, mostro que eu quero atravessar a rua. Se vou pegar algum ônibus e, pasmem vocês, eu saio lá de Osasco e vou até a Paulista, sozinho, eu e minha bengala. Graças a Deus por isso. (NARRADOR 3)

O surdocego Narrador 3 fez plaquinhas com a escrita em Braille e português. Escreveu as conduções que precisava para ir ao seu destino, e as orientações para a volta. Assim ele lê o Braille e verifica para onde quer ir. Quando necessita ele mostra essa mesma plaquinha para qualquer pessoa que estiver próxima a ele. Ao ler, a pessoa o guia para onde ele precisa ir. É uma medida simples que proporciona autonomia.

Foram construídas pelos guias intérpretes que o atendem uma série de plaquinhas. Na primeira está escrita: "Sou surdocego, pode me guiar?" E logo em seguida mostra a plaquinha do destino desejado. O guia-intérprete dele contou que essa primeira placa, passou por uma modificação. Nela estava escrito: Sou surdocego, pode me ajudar? Quando havia essa frase as 
pessoas davam dinheiro a ele e colocavam moedas em seu bolso. Foi quando o guia-intérprete percebeu que a informação gerava duplo sentido. Sobre esses recursos simples mais primordiais Galvão (2009) salienta:

Porém, embora todas as tecnologias convirjam, cada vez mais, para uma relação direta com as tecnologias de informática, não se pode deixar de estar atento às pequenas soluções artesanais do dia-a-dia, utilizadas em casa ou numa sala de aula, por exemplo, que, embora simples, muitas vezes têm o poder de solucionar problemas concretos e complexos. Soluções simples e artesanais que, frequentemente, apresentam um alto grau de eficiência e funcionalidade (GALVÃO FILHO, 2009, p. 157)

Sob tal perspectiva, é pertinente registrar experiências captadas em observações em uma Escola Municipal de Educação Bilíngue para Surdos. Também ressalto as possibilidades de contribuição facilitadas pelos recursos de tecnologia assistiva que conheci e produzi a partir das necessidades dos alunos surdocegos.

Presenciei recursos pedagógicos produzidos para os surdocegos, observados na pesquisa (observados 1 e 2) todos de suma importância para a apreensão da aprendizagem. Mesmo que aparentemente simples, causaram grande impacto na vivência destes alunos.

Os recursos foram produzidos pelo aluno surdocego em conjunto com a professora, a partir de experiências reais, para uso próprio na apreensão de conceitos. Em seguida, foi apresentado para a funcionalidade para o qual foi desenvolvido, e a utilização prática no seu cotidiano. Contêm uma forma escrita da grafia da Língua Portuguesa em relevo, para que o aluno surdocego vá se apropriando e memorizando conceitos durante o ano letivo. Sobre este aspecto Eustat (1999) ressalta:

Nesta perspectiva, as TA têm excelentes hipóteses de êxito se forem apropriadas, ou seja, eficazes (em relação às tarefas previstas, realizam o que delas se espera), contextuais (bem 
adaptadas ao meio e contexto de utilização) e consonantes (consistentes com o modo de vida e personalidade do utilizador). Seria redutor efectuar as escolhas sobre TA com base numa mera análise de tarefas (recursos pessoais vs. actividade a realizar) como se os indivíduos estivessem isolados do mundo; com efeito, o contexto do uso desempenha um papel fundamental, visto definir o mundo de relações do indivíduo. (EUSTAT, 1999b, p. 19)

No caso da surdocegueira é essencial o professor contextualizar a finalidade do material. Com a palavra "bala", por exemplo; foi realizada uma sequência didática significativa com o aluno surdocego (observado 1). A bala embrulhada foi colocada em sua mão (1), ele cheirou (2), descascou (3), colocou-a na boca (4) e degustou (5). Outra bala embrulhada foi colocada em sua mão (6), o objeto foi relacionado à palavra digitada pelo alfabeto datilológico (7), as letras do alfabeto datilológico foram associadas à escrita da Língua Portuguesa (8), a segunda bala foi colada no papel com ajuda da professora (9), Embaixo foram coladas as letras referentes à escrita (10) e ao lado foi colada a imagem referente ao sinal em Libras (11).

Depois dessa sequência, essa folha passou a compor o caderno de Língua Portuguesa. Todas as vezes que o aluno (observado 1) pega o caderno e passa por esta página; ele toca o objeto, confirma com a boca, faz o sinal em Libras "bala", toca a letra em português, passa a língua na letra e a reproduz no alfabeto datilológico tátil, evidenciando que associou à escrita. $\mathrm{E}$ assim, todas as páginas dos cadernos foram criadas, partindo de contexto e vivências.

Trago algumas imagens de materiais pedagógicos adaptados produzidos nestes moldes: 
Figura 1: Caderno de português com objeto de referência - bala

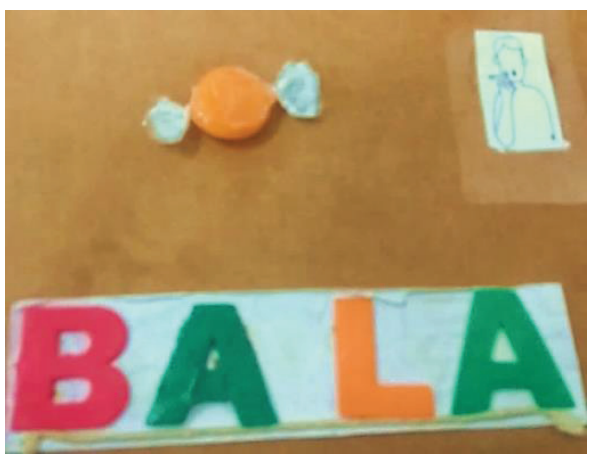

Fonte: Arquivo da pesquisadora

Figura 2: Caderno de português com objeto de referência - feijão

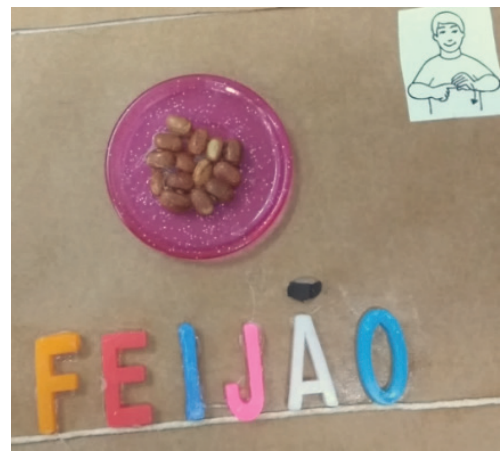

Fonte: Arquivo da pesquisadora

Figura 3: Caderno de matemática com identificação de numeração com pontos em relevo

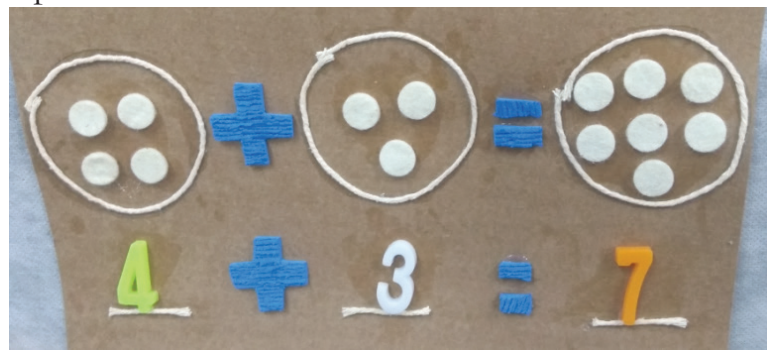

Fonte: Arquivo da pesquisadora 
Figura 4: Caderno de matemática com identificação de numeração com pontos em relevo

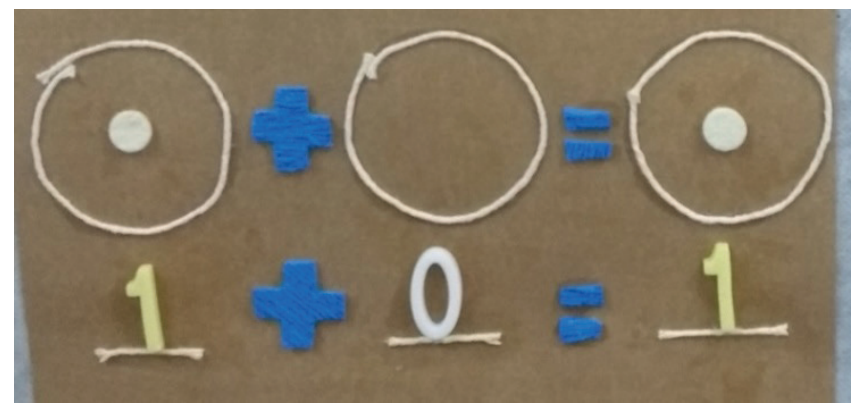

Fonte: Arquivo da pesquisadora

O aluno surdocego (observado 1), que produziu esses materiais juntamente com a guia-intérprete, tem uma singularidade, pois reconhece os elementos por meio do tato e, em seguida, faz a confirmação com o paladar. Faz a leitura de todas as atividades usando essa metodologia. Reconhece as letras do alfabeto da Língua Portuguesa e os números, e faz a transposição para o alfabeto datilológico tátil.

Figura 5: Alfabeto datilológico

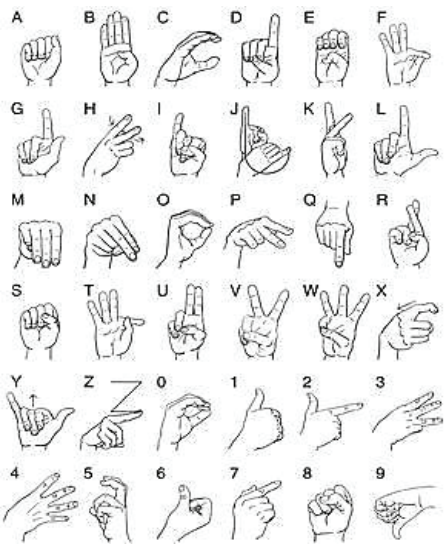

Fonte: Pinterest (2018, Online) ${ }^{2}$

2 Disponível na Internet em: < https://www.pinterest.pt/ pin/353321533258353273/>. Acesso em: 11 janeiro 2018. 
Nas atividades de português, nas quais precisa montar as palavras correspondentes ao objeto proposto, ele toca a letra, coloca-a na boca, gira sobre a língua até chegar à posição certa e depois realiza letra a letra a montagem da palavra.

Por vezes, ele coloca duas letras na boca e consegue identificar pela língua qual a letra correta. Chega a mastigar as letras, mas não engole. Só utiliza a língua nessa assimilação. É como se a língua fosse extensão do tato. É admirável olhar esse movimento e a precisão que o surdocego possui. Percebo que não é o gosto que o atrai, mas sim a textura e a forma. À medida que ele coloca a língua sobre as letras, mesmo sendo em papel espesso, no caderno adaptado para ele, as letras descolam e as vezes se soltam. Quando isso acontece, ele bate na mesa e emite alguns sons como sinal de protesto, até que alguém cole a letra novamente. Assim ele dá prosseguimento à atividade de leitura.

Após tais considerações, constata-se a necessidade de analisar vários aspectos para que o recurso produzido alcance os objetivos para o qual foi destinado. Na surdocegueira, é imprescindível promover a autonomia do aluno na utilização do material produzido para ele, dando suporte para que se evidencie o progresso em seu conhecimento. E assim, abre-se espaço para produção de novos materiais com outros desafios. Sobre esse aspecto Bersch (2008) evidencia:

Um atendimento completo de TA só ocorre quando é oferecido ao usuário um seguimento adequado. Este seguimento envolve ajustes, treinamentos, adequações, personalizações, adaptação ao crescimento e à mudança da condição física, e busca por novas oportunidades de atividade pessoal, que por sua vez geram novas necessidades, as quais podem ou não requerer novos recursos tecnológicos. (BERSCH, 2008, p. 16)

As formas de avaliação para a produção de recursos pedagógicos adaptados dentro da Tecnologia Assistiva são apresentadas de diversas maneiras. O documento produzido pelo MEC em 2010, destinado a recursos pedagógicos acessíveis e à comunica- 
ção aumentativa e alternativa, aponta alguns indicadores para a produção de materiais, a partir de perguntas norteadoras. São elas:

Quem é o aluno?

Quais as principais habilidades manifestadas pelo aluno e/ ou relatadas por seus familiares?

Quais as necessidades específicas deste aluno, decorrentes da deficiência ou imposta pelo ambiente escolar?

Como a família resolve os problemas decorrentes destas necessidades no ambiente familiar?

Que tipo de atendimento na área da saúde ou da educação o aluno já recebe e quais são os profissionais envolvidos neste atendimento?

Qual a impressão do professor da escola comum sobre o aluno?

Como está organizado o plano pedagógico do professor comum e quais são os objetivos educacionais e as respectivas atividades que ele propõe à sua turma?

Quais as necessidades relacionadas a recursos pedagógicos ou de acessibilidade apontadas pelos professores para atingir os objetivos propostos para o aluno?

Como é a participação do aluno nas atividades propostas à sua turma da escola comum? Ele participa das atividades integralmente, parcialmente ou não participa?

Quais barreiras existem à participação e ao aprendizado do aluno nas tarefas escolares e que poderão ser eliminadas com a utilização de recursos pedagógicos acessíveis?

Quais as condições de acessibilidade física da escola? Há rampas, banheiros adequados, sinalizações, entre outros?

Há auxílio de mobilidade para o aluno, tais como cadeira de rodas simples ou motorizadas, bengalas, corrimões nas escadas, auxílio para transferência da cadeira de rodas?

Os materiais pedagógicos são adequados? Há lápis e canetas ajustados à condição do aluno, alfabeto móvel, pranchas com letras e palavras, computador, teclados e mouses especiais, acionadores, órtese de mão funcional para escrita e digitação, ponteiras de boca ou cabeça? (SARTORET'TO, 2010, p. 4-5) 
De posse dessas informações, tanto o professor da sala de aula regular, quanto o professor de Atendimento Educacional Especializado, pode obter informações valiosas para a elaboração de um Plano de Atendimento Educacional Especializado (AEE) consistente inclusive, para a seleção de recursos pedagógicos necessários para esse atendimento.

O professor, sensível às necessidades do aluno e conhecedor de informações pessoais sobre eles, toma posse de procedimentos inclusivos. O participante a seguir narra algumas adequações feitas por uma professora no ensino básico:

Faziam algumas adaptações, imprimiam em uma impressora em que a letra saía maior, bem grande e bem preta, para eu conseguir enxergar. Tinha uma lupa que me auxiliava naquela época, não tinha nenhum tipo de Tecnologia Assistiva como a gente tem hoje [...] depois que eu passei a perder a visão aí que eu sofri um pouco. Foi bem difícil, mas antes eu usava óculos, um óculos de grau bem alto e os materiais precisavam ter uma letra maior. Era bem difícil. Eu precisava de uma lupa eletrônica, para aumentar uma letra. O material que estava usando era bem trabalhoso. (NARRADOR 3)

O surdocego não reconhece esses recursos de adaptação como tecnologia assistiva. Ele menciona uma evolução, quando diz: "Não tinha nenhum tipo de Tecnologia Assistiva como a gente tem hoje". Portanto, deixa evidente que o uso dos recursos é essencial, mas relata as dificuldades também. A surdocega Narradora 2 fala sobre as adaptações realizadas no ensino superior, pelos professores e intérpretes:

Tinha prova e só eu de surdocega. Então, os ouvintes respondiam as perguntas e as questões eram dissertativas. Mas, minha prova era adaptada. As questões eram de múltiplas escolhas, eu lia as respostas e colocava um $\mathrm{X}$ naquela que eu julgava que estava certa. [...] A professora falava e a intérprete traduzia para mim através da Libras, depois o [...] 
foi meu intérprete. Eu tive dois intérpretes de Libras só. Tinha prova de alternativa, só. Mas, depois de dois anos, tive que parar de estudar. Mas, naquela época não tinha o Braille ainda, e nem a Libras tátil também. Então eu tinha que estudar muito. Eu tinha que ler muito e, às vezes, eles usavam o recurso de DVD, com as matérias e a janela em Libras. E era assim que eu aprendia. (NARRADORA 2)

Compreendo que o conhecimento da surdocegueira, na época de estudos da surdocega, ainda era escasso se comparado aos dias atuais. Ela relata que só havia intérpretes de Libras e que o Braille não era utilizado. Não havia a presença de guias-intérpretes, nem a comunicação por meio da Libras tátil. Contudo, pelo seu esforço e recursos adaptados de que dispunha, ela conseguiu desenvolver a aprendizagem. Uma das melhores alunas da sala.

Algumas habilidades e competências são requeridas pelos professores para a produção de recursos pedagógicos. O Artigo 18 da Resolução 2/2001 registra:

Perceber as necessidades educacionais especiais dos alunos; Flexibilizar a ação pedagógica nas diferentes áreas de conhecimento;

Avaliar, continuamente, a eficácia do processo educativo;

Atuar em equipe, inclusive com professores especializados em educação especial. (BRASIL, 2001, p. XX)

A narrativa abaixo relata o trabalho do professor na promoção do conhecimento pelas habilidades citadas acima, e o quanto marcou a vida deste surdocego:

Com a lupa eu tinha mais autonomia, por exemplo. Eu podia me esforçar e vencer todos esses limites com esses recursos, porque não existia tecnologia nessa época. Por isso, foi muito importante essa interação. Saber que o professor fazia no papel com uma letra maior, saber que os professores de diversas disciplinas tinham essa preocupação 
com meu aprendizado, mas, principalmente, com a minha comunicação [...] o professor me ensinava as palavras, me dava os sinais, isso tudo foi muito importante para minha vida. (NARRADOR 3)

Tive o privilegio de vivenciar esses aspectos de produção de material pedagógico adaptado para surdocegueira e, também, a produção de um roteiro de plano de AEE a partir das necessidades do aluno observado 1 , em uma escola de educação bilíngue para surdos.

\section{CONSIDERAÇÕES FINAIS}

A efetiva inclusão de surdocegos tem passado por um processo de apropriação. Ainda há poucos profissionais qualificados para esse trabalho, mas os esforços tem sido incessantes. É necessário que educadores se proponham a adaptar materiais e que tenham compromisso com a educação e o desenvolvimento do surdocego.

As possibilidades de atendimento são inúmeras e existem referenciais consistentes que trazem pistas valiosas de como acontece o atendimento efetivo. As perspectivas de quem vivencia são essenciais para a adequação de recursos de tecnologia assistiva. Nesse aspecto os surdocegos trazem informações importantes por meio das narrativas informações importantes.

As experiências vivenciadas nas observações oferecem possibilidades de inclusão a partir das necessidades dos surdocegos e resgatam as primícias do atendimento que parte do principio da avaliação das necessidades individuais do aluno.

O plano de Atendimento Educacional Especializado é essencial para verificação de princípios que norteiam todo o atendimento. A parceria entre o professor da sala de AEE, o educador da sala de aula e o guia-intérprete se faz primordial. Juntos eles podem elaborar estratégias e recursos que irão favorecer o aluno surdocego.

Dentro de todas as possibilidades trazidas aqui penso que a inclusão de surdocegos é emergente e depende de vários fatores. É desafiadora mas totalmente possível a partir de educadores atentos e sensíveis a sujeitos impares em constante evolução. 


\section{REFERÊNCIAS}

BERSCH, Rita de Cássia Reckziegel; PELOSI, Miryam Bonadiu. Portal de Ajudas Técnicas Para Educação: equipamento e material pedagógico para educação, capacitação e recreação da pessoa com deficiência física: tecnologia assistiva: recursos de acessibilidade ao computador II. Secretaria de Educação Especial. Brasília: ABPEE-MEC : SEESP, 2006. Disponível na internet em : < http://www.educadores.diaadia.pr.gov.br/arquivos/File/pdf/ tecnologia_assistiva.pdf $>$. Acesso em: 26 janeiro 2018.

BERSCH, Rita. Recursos pedagógicos acessíveis: Tecnologia Assistiva (TA) e processo de avaliação nas escolas. Disponível na internet em : <http://www. assistiva.com.br/Recursos_Ped_Acessiveis_Avaliacao_ABR2013.pdf >. Acesso em: 26 janeiro 2018.

BRASIL. Parecer CNE/CEB 17/2001. Diário Oficial da União. Disponível na internet em: < http://portal.mec.gov.br/cne/arquivos/pdf/CEB017_2001. pdf $>$. Acesso em: 22 agosto 2018.

BRASIL. Resolução do Conselho Nacional de Educação (CNE) no 2, de 11 de fevereiro de 2001. Brasília, 2001a. Disponível na internet em: <http:// portal.mec.gov.br/ seesp/arquivos/pdf/res2_b.pdf $>$. Acesso em: 25 janeiro de 2018.

CLANDININ, D. Jean; CONNELLY, F. Michael. Pesquisa narrativa: experiências e história na pesquisa qualitativa. Trad. Grupo de Pesquisa Narrativa e Educação de Professores ILEEL/UFU. 2a ed. Uberlândia: EDUFU, 2015. CRESWELL, J. W. Projeto de pesquisa: método qualitativo, quantitativo e misto. 3. ed. - Porto Alegre: Artmed, 248 p. 2010.

EUSTAT, 1999b. Educação em tecnologias de apoio para utilizadores finais: linhas de orientação para formadores. Disponível na internet em: < http://www.siva.it/research/eustat/eustgupt.html >. Acesso em: 03 setembro 2018.

GALVÃO FILHO, Teófilo Alves. Tecnologia Assistiva para uma escola inclusiva: apropriação, demanda e perspectivas. Recurso Eletrônico, 2009.

SARTORETTO, Mara Lúcia. A Educação Especial na Perspectiva da Inclusão Escolar: recursos pedagógicos acessíveis e comunicação aumentativa e alternativa. Brasília: MEC-SEE, 2010.

\section{SOBRE A AUTORA}

Mestre em Educação (UMESP), Especialista em Tradução e Interpretação Libras/Português. Especialista em Docência do Ensino Superior (UNICASTELO) Graduada em Pedagogia (UMESP). Intérprete e guia-intérprete. Trabalha como docente no Centro Universitário Sant'Anna (UniSant'Anna). E-mail: nanevilela@hotmail.com 